\title{
Comparing the effectiveness of fire extinguisher virtual reality and video training
}

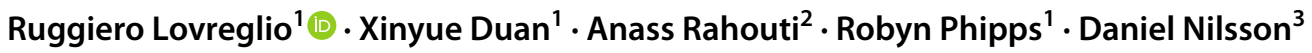

Received: 11 December 2019 / Accepted: 12 May 2020 / Published online: 22 May 2020

๑) Springer-Verlag London Ltd., part of Springer Nature 2020

\begin{abstract}
Fire is a major hazard in built environments. Fires in buildings cause fatalities, serious injuries and tremendous damage. Most fires can be extinguished in the early stages of the fire's development, with the right equipment and correct use of the equipment. However, as there can be as little as a few minutes between a fire starting and very dire consequences, rapid and correct responses are critical. Implementing effective training solutions is necessary to enable members of the public, who are not experts in fire safety, to use a fire extinguisher correctly. This can assist to build resilience to fires. In recent decades, virtual reality (VR) has aroused the fire safety community's attention, as a smart, safe and effective training method compared to the traditional methods of lectures, non-interactive videos, and brochures. VR has been used for training for fire emergency preparedness and to collect data about evacuee decision-making, but VR has rarely been applied to a fully immersive training experience about fire extinguishers operation steps. Fire extinguisher operation steps are Pull, Aim, Squeeze and Sweep. Each step is critical to quickly extinguish a fire. This paper compares fire extinguisher training using a VR simulation with a non-interactive training video and evaluates the trainees learning of a fire extinguisher's basic operation steps, in terms of knowledge acquisition, retention of information and change of self-efficacy. The results showed that the VR trainees scored better than video trainees, in terms of knowledge acquisition, even if the same trend was observed for long term retention of information. It was also observed that VR training provided a higher increment of self-efficacy right after the training. The VR group participants had maintained the same level of self-efficacy even 3-4 weeks after the training, while the video group had shown a significant drop of self-efficacy.
\end{abstract}

Keywords Fire safety $\cdot$ Fire extinguishers $\cdot$ Virtual reality $\cdot$ Serious games $\cdot$ Training

\section{Introduction}

The number of recent building fire incidents that have resulted in fatalities, serious injuries and costly damage to property has focused concern on methods to prevent fires and promote fire safety. For instance, 3619 reported structural fire incidents occurred in New Zealand homes between 2014 and 2015 (Duckworth et al. 2016). These fires caused 18 deaths and many non-fatal injuries. The lack of personal

Ruggiero Lovreglio

R.Lovreglio@massey.ac.nz

1 School of Built Environment, Massey University East Precinct, Dairy Flat Highway (SH17), Auckland 0632, New Zealand

2 Faculty of Engineering, University of Mons, Mons, Belgium

3 Department of Civil and Natural Resources Engineering, University of Canterbury, Christchurch, New Zealand fire safety skills in the general public has been identified as a contributing factor for fire-related fatalities and injuries (De Gloria et al. 2014). Fire safety design measures include early detection and containment to prevent the spread of fire between neighbouring tenancies and fire extinguishing systems. Many buildings have sprinklers to dampen a fire or smoke removal systems. However, these are not common in homes, schools or low rise and older buildings.

Educating people on fire safety skills has been identified as a key strategy to save lives and reduce injuries associated with fires, and to build resilience to this disaster. However, finding an effective training method for educating building occupants has been a challenge for safety educators. In fact, several traditional approaches including lectures, seminars, evacuation drills, non-interactive videos, brochures, and online exercises are being used to teach the general public how to act in a fire emergency and how to manipulate firefighting tools. However, those traditional approaches are costly and 
do not seem to be the ideal training solution with regards to knowledge acquisition and retention.

In most public buildings, fire and building codes require fire extinguishers to be provided, and many households voluntarily have one or more fire extinguishers available. Fire extinguishers are very important protection devices due to their high efficiency, easy availability and portability. Eighty per cent of fire incidents, at their early stage, could be controlled and put out by using such devices (NZG 2019). However, only $40 \%$ of the general public can use a fire extinguisher correctly (Poole et al. 2012). Regrettably, some people are injured while using fire extinguishers because of their lack of knowledge about the operation steps of such devices (Poole et al. 2012). Fire extinguishers are single-use items, which limits the amount of practice that the general public can have with the use of a fire extinguisher. According to Poole et al. (2012) and Månsson (2018), most people have never used an extinguisher until they are faced with fire. An emergency is obviously not the ideal circumstance to be attempting a new skill, and there is no time to read the instructions when faced with a developing fire. To overcome these significant issues, safe and effective training is required to educate the general public on the basic firefighting tasks.

Digital technologies are providing new solutions to enhance the effectiveness of training. Technologies like virtual reality (VR) could be an alternative training solution that offers advantages, such as proposing safe training environments and cost-effective solutions (Feng et al. 2018; Lovreglio and Kinateder 2020). VR technology can help bridge the gaps in existing training approaches. The use of VR applications for training is increasing at a high rate and VR applications can be effective for safety training. For instance, Lebram et al. (2009) study on firefighter training showed that participants found the VR experience more engaging than conventional training. Similarly, Chittaro and Buttussi (2015), Burigat and Chittaro (2016) and Chittaro et al. (2018), compared the effectiveness of VR for educating aircraft passengers on safety measures, against conventional demonstration based training. The results of those studies showed that the VR approach was superior to the traditional approach in terms of knowledge acquisition and retention.

According to the literature, VR technologies have a vital role in the transformation of educational systems regarding how people can learn new skills effectively (Inoue 1999). Some scholars believed that VR could be the most effective method to learn and retain information (Taitt 1993), as VR enables difficult tasks to become simpler when students practice in the virtual world (Inoue 1999) and VR provides a highly interactive environment in which the learner is an active participant in the digital learning environment (Kim et al. 2001). A recent study, by (Lee 2011), highlighted how VR positively affects the cognitive and affective domains of learners. While most of this previous research focused on the application of VR in the educational domain, this paper reports on a project focused on the assessment of a VR technology for training purpose.

VR could be an ideal solution for training people on the usage of fire extinguishers. Although the effectiveness of VR applications in the safety domain has been verified in existing research studies (Tate et al. (1997), Feng et al. (2018) and Lovreglio et al. (2018)), to the best of our knowledge, only one previous research effort (Månsson 2018) has investigated the effectiveness of a VR pre-training before operating a real fire extinguisher. As such, there is no study investigating the effectiveness of VR training for fire mitigation, in terms of knowledge acquirement and retention. On the other hand, there is no comparison of possible VR training solutions with traditional training solution focusing on the use of a fire extinguisher.

This research work aims at assessing the effectiveness of an existing VR application to train people on the operating steps of fire extinguishers and to compare it with non-interactive video training. The effectiveness of the two training solutions was assessed by comparing the knowledge acquisition of the two groups immediately after the training, and their knowledge retention 3-4 weeks after the training was completed. Finally, the two training solutions were compared in terms of their impact on participants' self-efficacy (i.e. their belief in their ability to correctly use a fire extinguisher), recommendation efficacy, and recommendation simplicity in line with the Protection Motivation Theory (Maddux and Rogers 1983).

This paper is organized as follows: Sect. 2 provides background information on the use of VR and serious games as a training tool to enhance people's fire safety skills and studies comparing VR training with alternative training for fire and evacuation safety purposes. Section 3 describes the material and methodology used in this study. Results are presented in Sect. 4, while the discussion around the results, limitations of the present research, and directions for future developments are presented in Sect. 5. Finally, Sect. 6 concludes the paper.

\section{Background}

Several research studies related to virtual environments (VE) fire safety training simulators have been reported in the literature. Many highlighted the benefits of these tools compared to traditional training methods. Tate et al. (1997) reported promising outcomes of VE as a training tool for shipboard firefighting training mission rehearsal. Another study by Smith and Ericson (2009) proposed VE as a tool for enhancing children learning about fire hazards and to practice escape techniques. This study assessed children's motivation prior to the VR-based fire safety training and 
after being exposed to the VR simulation. The results indicated that children were more engaged by the game-like learning training and that they self-reported that they found the experience fun and intriguing. Serious games have also been used to increase personal fire safety skills while evacuating different types of VE (Cha et al. 2012; Chittaro 2016; Chittaro and Ranon 2009; Kinateder et al. 2014; Rüppel and Schatz 2011; Smith and Trenholme 2009; Silva et al. 2013; Xu et al. 2014).

Various studies have compared the above-mentioned methods in various safety domains to assess the effectiveness of VE training simulators against traditional training approaches.

Lebram et al. (2009) proposed a game training simulator to train firefighters for Breathing Apparatus Entry, and to develop systematic search and rescue strategies. The game environment is a CAVE (Cave Automatic Virtual Environment) where the player is surrounded by four screens giving a $360^{\circ}$ view of a virtual world. The study involved 31 firefighters. They were divided into two experimental groups. The game was administered to the first experimental group, while the second group has been exposed to a traditional training method. Overall, the results show that participants had a more enjoyable experience and felt more confident about their rescue technique when using the VR training tool.

Chittaro and Buttussi (2015) investigated the effectiveness of an immersive game for educating passengers about aviation safety against a safety card. The results showed that the immersive serious game was superior to the safety card in terms of knowledge acquisition and retention of information 1 week after the training was completed. It was noted that the SG was more engaging and fear-arousing than the safety card. Similarly, Burigat and Chittaro (2016) used a $\mathrm{VE}$ as a tool to teach spatial knowledge for evacuation purposes using aviation as a case study. They compared this approach to a printed diagrammatic map. Results showed that participants who used the VE-based tool acquired a better spatial knowledge, compared with the group who learned from the printed maps when they were asked to pinpoint their assigned position in the environment. It was also noticed that active navigation produces a better performance improvement in a subsequent virtual evacuation compared with the conventional maps.

Lebram et al. (2009) highlighted that the VE-based tools are often perceived as more enjoyable, easier to comprehend and more effective, than printed maps when active navigation is available. Another study by Chittaro et al. (2018) explored how VE-based tools administered on smartphones were able to enhance aircraft passengers' safety training by making the traditional briefing cards interactive. The results showed that the participants who used the interactive briefing cards on smartphones were able to transfer the presented safety knowledge to the real world and don an aviation life preserver role faster and with fewer errors, than participants who used the conventional briefing card. Moreover, the VEbased tool was quoted as more engaging, easier, and more effective than the conventional briefing card. Finally, participants who were administered the VE-based tool attained a higher level of self-efficacy.

Kinateder et al. (2013) studied the impact of additional VR behavioural training on self-evacuation during a virtual fire scenario in a road tunnel. Three groups of volunteers took part in the experiment; namely, the control group, the informed group and the VR training group. The first group only filled subjective questionnaires. The second group additionally read an information sheet. The third group was exposed to an additional behavioural VR training in a simulated tunnel scenario. One week later, all participants conducted a drive through a real road tunnel in which they faced a collision of two vehicles and intense smoke. The results showed that the second and third groups' participants evacuated themselves more reliably from the tunnel than those of the first group. A 1-year follow-up questionnaire showed a decrease in knowledge for all groups, but still, the third group had somewhat more safety knowledge than the two other groups.

In summary, previous research studies have shown that VE serious games play an important role in safety training and are of benefit for people exposed to such tools. Nevertheless, fully immersive VE has been applied only in a single research study (Månsson 2018). This study has shown the effectiveness of a VR pre-training before operating a real fire extinguisher. However, there is no available research investigating the effectiveness of VR training for fire extinguishing as well as a comparison between VR training and traditional training such as non-interactable video training.

\section{Materials and method}

This research investigated the effectiveness of VR training and non-interactive video training on how to use a fire extinguisher using the PASS manoeuvre (i.e. Pull, Aim, Squeeze and Sweep). The traditional training and VR training tools are introduced in Sects. 3.1 and 3.2, while the research method steps and data collection and analysis are presented in the remaining sub-sections.

\subsection{Traditional training}

The traditional training was carried out using a non-interactive video showing the PASS procedure steps (Bass 2014). This video is one of the most popular videos on YouTube on this topic. It briefly introduced the four steps to operate a fire extinguisher, including Pull (see Fig. 1a), Aim (see 
Fig. 1 PASS steps as shown through the video training (Bass 2014)

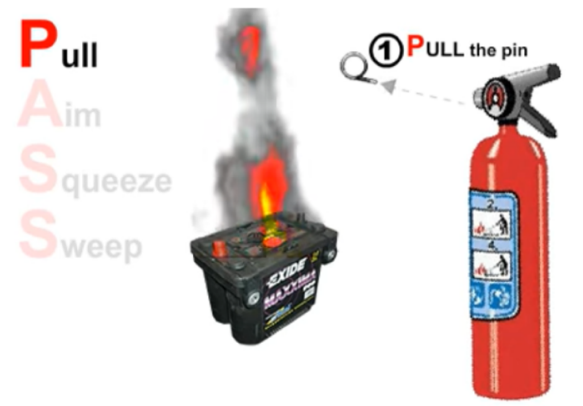

(a) Pull the pin of the fire extinguisher (Screenshot taken at 00:02 in the YouTube video)

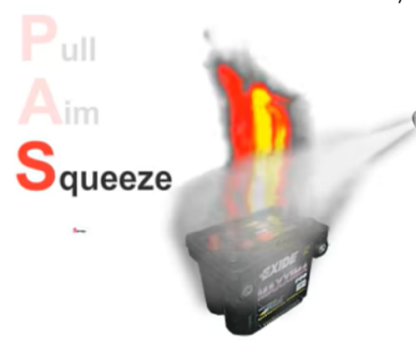

$=$

(c) Squeeze the handle of the fire extinguisher (Screenshot taken at 00:09 in the YouTube video)
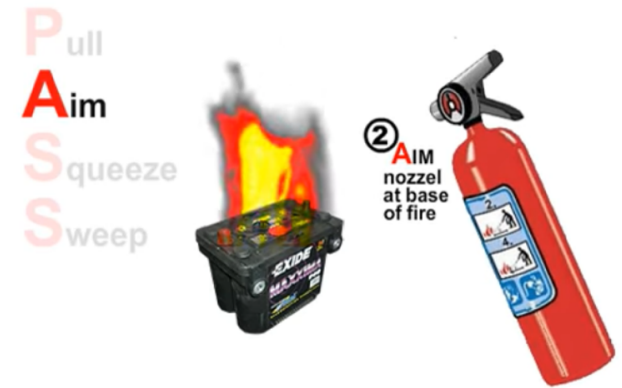

(b) Aim at the base of the fire (Screenshot taken at 00:05 in the YouTube video)

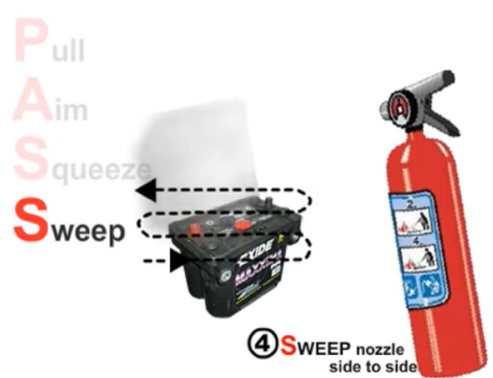

(d) Sweep the nozzle side to side (Screenshot taken at 00:17 in the YouTube video)
Fig. 1b), Squeeze (see Fig. 1c) and Sweep (see Fig. 1d). This video presented the four steps one after another, showing an animation on how to perform each step. It was selected for this research as it is easy to be understood by participants through its vivid animations and simulated sound effect. The link for the video is provided in Bass (2014). The video was shown to the participants on a 15.6' laptop screen.

\subsection{VR training}

The VR training was done using an existing VR training tool called "PASS". This tool was designed and developed by MAMMOTH VR. This VR application summarizes the core steps (i.e. Pull, Aim, Squeeze and Sweep) of using fire extinguishers, where participants can easily learn these steps. Four types of fire incidents are designed in different scenarios, namely warehouse, electrical, office and worksite. All the actions to perform by the trainee were the same in each scenario. For instance, Fig. 2 illustrates those steps for the warehouse scenario. The first step consists of collecting the fire extinguisher from the fire station (step "a" in Fig. 2). Then, the trainee must follow the PASS procedure to put out the fire (steps "b" to "d" in Fig. 2). In this study, the warehouse scenario is used to familiarize the trainee with the virtual experience and with the simulator controls.

In this study, we used the HTC Vive VR equipment to visualize the virtual environment. It comes with a headset, two sensors and two controllers. The sensors track the position of the headset and the controllers within a specific area that is calibrated before carrying out the experiment according to the available space in the premise dedicated to the experiment. To use the HTC Vive VR apparatus, minimum system requirements are suggested by the system manufacturer (Trusted Reviews 2018).

\subsection{Research design process}

To compare the effectiveness of the VR training with traditional training, three evaluation tests were designed to evaluate participants' knowledge acquisition and retention of information, namely pretest (before the training), post-test (immediately after the training) and retention-test (3-4 weeks after the training). Figure 3 presents a flow chart showing the research design process. The differences between the two training solutions' research process are highlighted in green in this figure. A questionnaire was designed to collect information during each test for both pieces of training.

The pretest questionnaire included two parts. The first part collected background information on participants' age, their previous experience and training with fire extinguishers, as well as their gaming experience (i.e. how often they play video games) and their familiarity with VR technology; while the second part assessed the participants' knowledge about the operation steps of a fire extinguisher and their 
Fig. 2 PASS steps as shown through the VR training. a Fire extinguisher station, b-d PASS steps as experienced by a VR participant

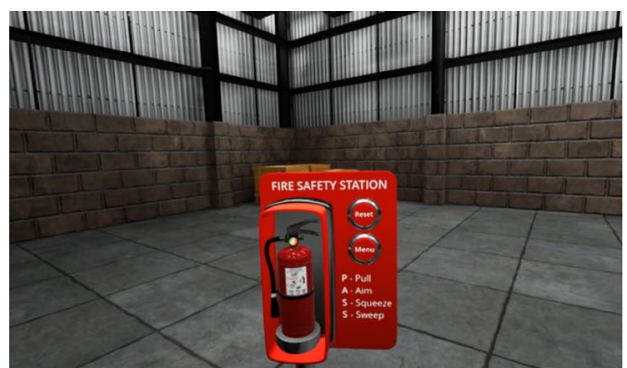

(a)

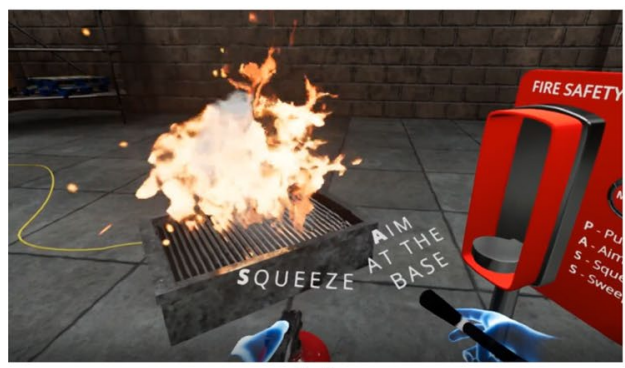

(c)

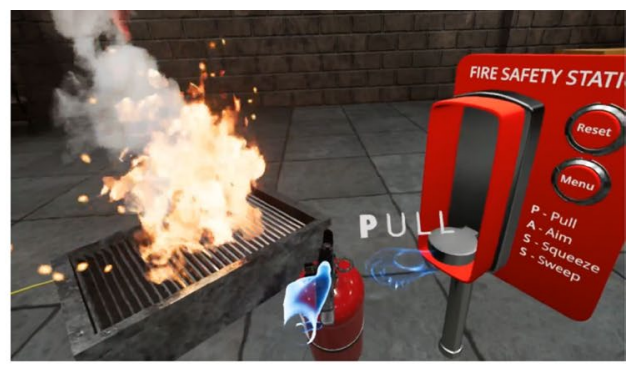

(b)

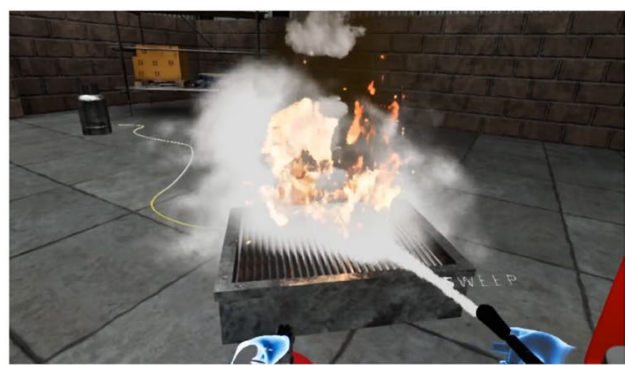

(d)
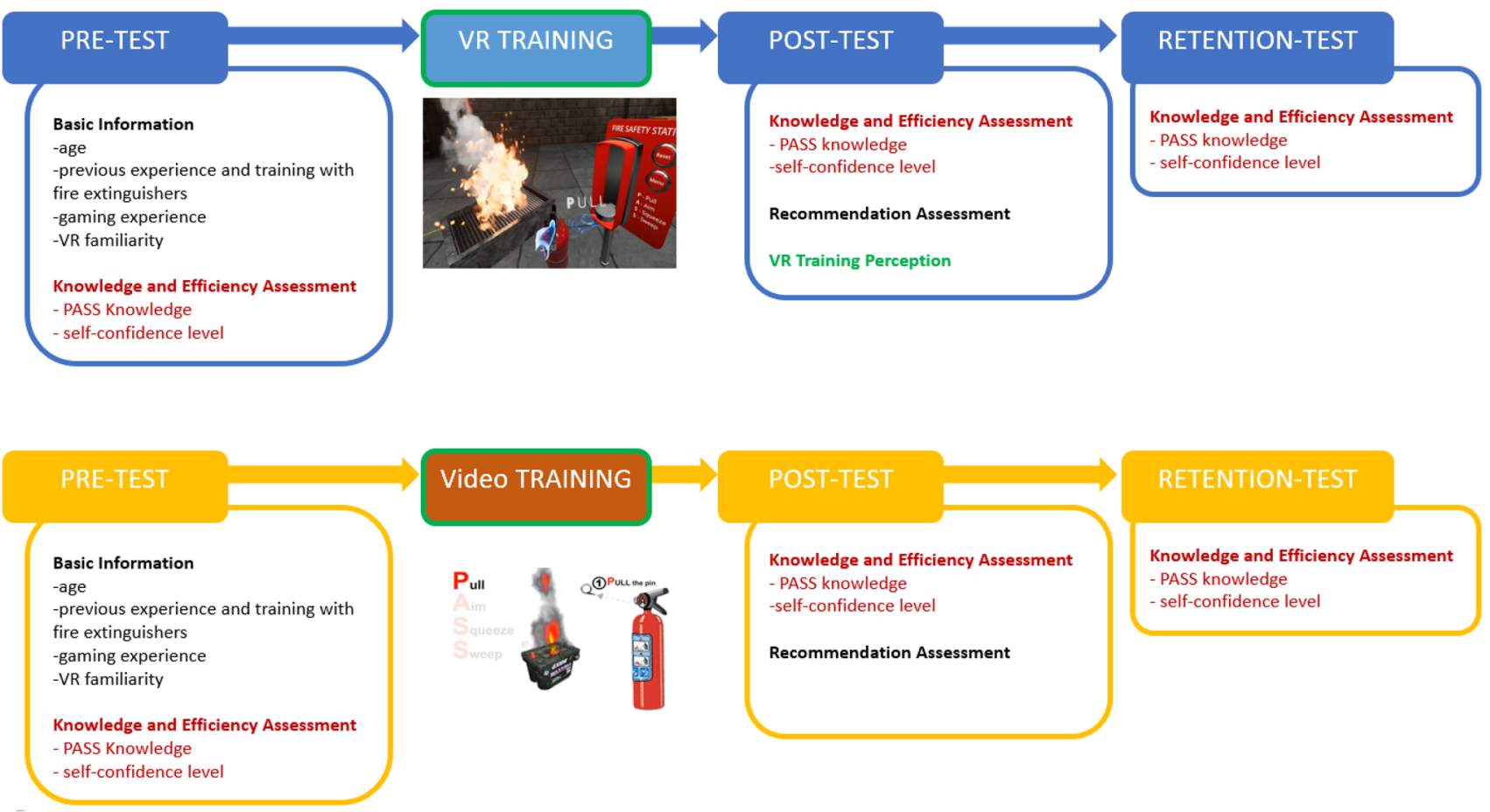

Fig. 3 Research design process

self-efficacy level about the use of fire extinguishers (see Sect. 3.4).

After completing the pretest questionnaire, the participants carried out the training either using VR or the video under the supervision of a researcher. The researcher's role in the VR training was limited to providing help about the game controls to the participants if necessary. It was decided that each participant did training using either VR or video, as a cross over design (i.e. participants experiencing both methods in a randomised order) would have contaminated the learning from the two training methods, and would not have enabled a comparison of the effectiveness of the individual training methods. 
After the training was completed, the participants were asked to fill out the post-test questionnaire to assess participants knowledge about the operation steps of a fire extinguisher and their self-efficacy level about the use of fire extinguishers. The participants were then asked to assess the recommendations provided during the training. Finally, the VR group was asked to compare the VR training with traditional training procedures (see Sect. 3.4). Three to four weeks after the training were completed, the participants were asked to fill the last test called retention-test to evaluate their knowledge retention and their self-efficacy level.

\subsection{Data collection and questionnaire}

The comparison between the VR training and the video training was made considering several measurements:

(a) Knowledge acquisition;

(b) Knowledge retention,

(c) Self-efficacy,

(d) Recommendation efficacy, and

(e) Recommendation simplicity.

To measure participants' knowledge, the participants needed to describe the specific steps of the PASS procedure and answered what should they pay attention while putting out a small fire. Participants were asked to answer open-ended questions. This avoided prompting with possible answers or limited responses if using close-ended questions. The open-ended knowledge answers were coded by one of the researchers to provide a score ranging from 0 to 5 , depending on how many items from the following list were mentioned by the participants:

- PASS procedure name;

- Pull the pin;

- Aim at the base of the fire;

- Squeeze the handle;

- Sweep side to side.

An example of the scoring procedure is illustrated in Table 1.
The remaining data was collected using closed-ended questions and using Likert scales assessing: (1) fire extinguishing self-efficacy; (2) recommendation efficacy and simplicity; and (3) VR training perception.

The scored were given by a single raterperson with expertise in fire extinguisher use. However, to ensure the reliability of the measurements, 30 observations were scored by a second person with expertise in fire extinguisher use. The Pearson correlation coefficient between the two people rating the tests was 0.95 and a kappa of 0.87 , showing a very good level of agreement and thus the reliability of the selected measuring approach.

The (c-e) measurements were selected based on the existing literature comparing different safety training solutions (Chittaro and Sioni 2015; Leder et al. 2019) which are based on the Protection Motivation Theory (Maddux and Rogers 1983). This theory models how people are motivated to protect themselves from risks depending on the threat appraisal and coping appraisal processes. In this work, we focus on how the two different training solutions impact the coping appraisal process. This process is characterized by self-efficacy (i.e. the individuals' beliefs about whether they are able to correctly use a fire extinguisher), recommendation efficacy (i.e. the individuals' beliefs about whether the recommended instructions will be effective to extinguish a fire) and recommendation simplicity (the individuals' beliefs about whether the recommended instructions are easy enough to follow to extinguish a fire).

Two items were used to assess fire extinguishing selfefficacy. The participants were asked to rate their level of agreement ( -3 strongly disagree, +3 strongly agree) with the following statements:

- I clearly know the correct steps of using a fire extinguisher;

- I am confident that I am able to effectively use a fire extinguisher to put out the fire.

Then, the self-efficacy for each participant was calculated by the average of the two scores.

Five items were used to assess the recommendation efficacy and simplicity provided by the VR application and the video. The participants from both groups were asked
Table 1 Example of how openended knowledge answers were scored

\begin{tabular}{|c|c|c|c|c|c|c|c|c|}
\hline Participant & $\# 1$ & $\# 2$ & $\# 3$ & $\# 4$ & $\# 5$ & \#6 & $\ldots$ & \#93 \\
\hline PASS & & & & & & 1 & & \\
\hline Pull & & & & & 1 & 1 & & \\
\hline Aim at the base & & & & & & 1 & & 1 \\
\hline Squeeze & & 1 & & & 1 & 1 & & 1 \\
\hline Sweep & & & & & & 1 & & 1 \\
\hline Total & 0 & 1 & 0 & 0 & 2 & 5 & $\ldots$ & 3 \\
\hline
\end{tabular}


to rate their level of agreement ( -3 strongly disagree, +3 strongly agree) with the following sets of statements:

Recommendation efficacy

- The recommendations provided in the training experience are useful for my safety;

- The provided recommendations will allow me to effectively use the fire extinguisher.

Recommendation simplicity

- I could easily learn the recommendations provided in the virtual experience;

- I could easily remember the recommendations provided in the virtual experience;

- I could easily carry out the recommendations provided in the virtual experience.

The recommendation efficacy and simplicity for each participant was calculated by averaging the scores of the two sets of items.

Three items were used to assess how the VR group perceived the VR training compared with traditional training. As such, the participants from the VR group were asked to rate their level of agreement ( -3 strongly disagree, +3 strongly agree) with the following statements:

- I found this fire extinguisher simulation more engaging than traditional training tools (like fire drills, non-interactive videos, health and safety inductions, recommendation leaflets, and seminars);

- It was easier to remember the fire extinguisher recommendations provided in this simulation than those provided with traditional training tools;

- I prefer the fire extinguisher simulation over traditional training tools.

\subsection{Participants}

The experiments involved 93 participants (48 females, 42 males and 3 participants who preferred not to specify their gender). All participants were volunteers. They did not receive compensation for their participation in this study. They were recruited randomly in Auckland (New Zealand) at Massey University's Albany campus and in several public libraries. After 3-4 weeks after the training, the same participants were contacted again to complete the retention-test. However, only 45 of them completed the second evaluation test (20 for the VR group and 24 for the video group).

The participants' age ranged from 21 to 61 years old for the VR group, while it ranged from 21 to 65 years old for the video group. Regardless the participants were randomly assigned to one of the two groups, the ages between the two groups are different ( $u$ test, $p$ value $=0.02$ ). The VR group seemed to have older participants (mean $=38.21$ and standard deviation $=12.91)$ than the video group $($ mean $=32.34$ and standard deviation $=12.60$ ). As such, it is necessary to verify if the age might give any impact on the findings.

The participants' previous fire extinguisher training, their usage of fire extinguishers, and their gaming and VR experiences are illustrated in Fig. 4.

\section{Results}

\subsection{Knowledge assessment}

In this section, the knowledge scores obtained by the participants are analysed by splitting them depending on the group (i.e. VR versus video) and when the assessment occurred, i.e. before the training (Pre), after the training (Post) and after 3/4 weeks (Ret). The result is illustrated in Fig. 5. Given that the knowledge is measured using an ordinal scale from one to five, Mann-Whitney $u$ test was used to compare whether there are statistical differences between the experimental groups (i.e. VR and Video) and

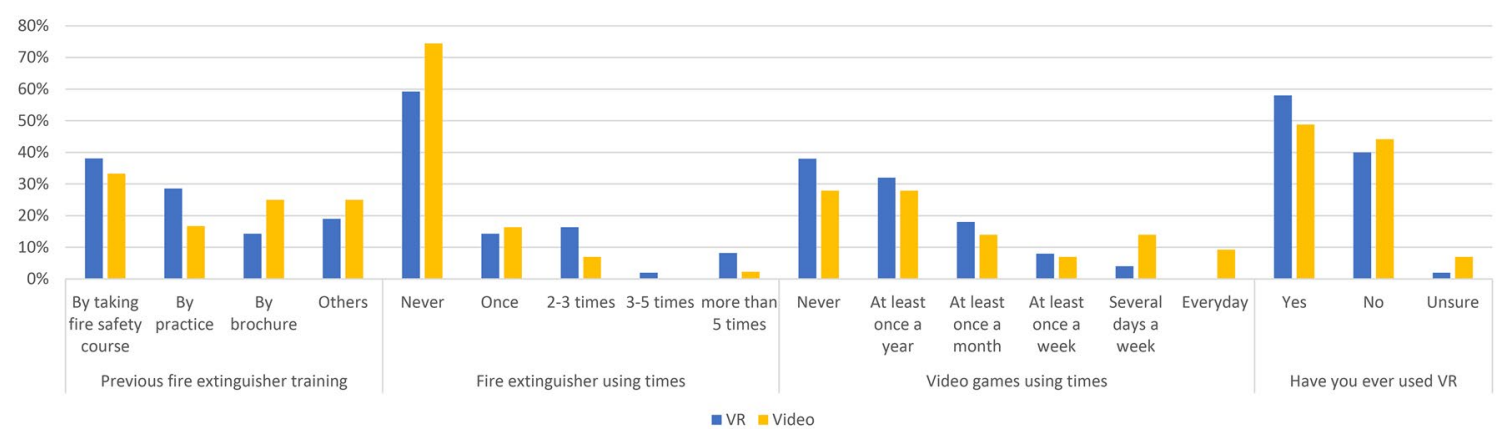

Fig. 4 Participants' previous training and use of fire extinguishers and gaming and VR experiences 


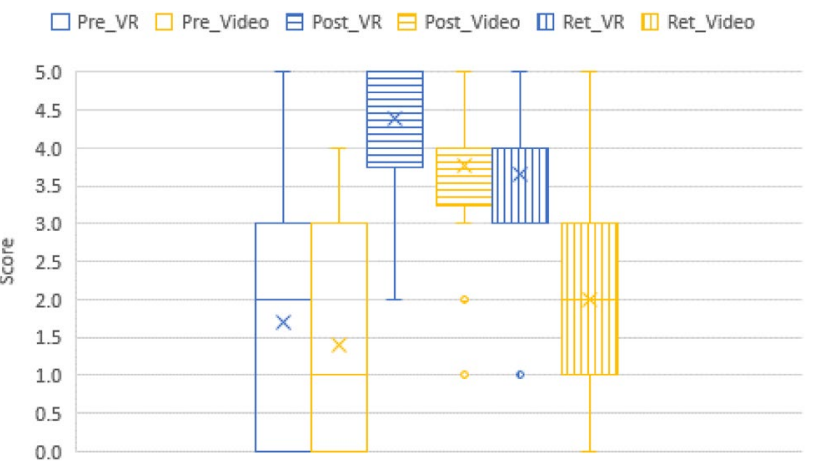

Fig. 5 Participants' scores before the training (Pre), after the training (Post) and after 3/4 weeks (Ret) for the VR and Video training

Table 2 Comparison of the knowledge scores before the training (Pre), after the training (Post) and after 3/4 weeks (Ret) for the VR and video training

\begin{tabular}{llllll}
\hline & \multicolumn{2}{l}{ Pre versus post } & & \multicolumn{2}{l}{ Post versus ret } \\
\cline { 2 - 3 } & VR & Video & & VR & Video \\
\hline $\mathrm{N}$ & 94 & 90 & & 66 & \\
$\mathrm{U}$ & 222.5 & 189 & & 275.5 & 159 \\
Asymp. sig. (2-tailed) & 0.000 & 0.000 & & 0.005 & 0.000 \\
Eta-squared & 0.501 & 0.515 & & 0.121 & 0.370 \\
\hline
\end{tabular}

Table 3 Comparison between knowledge scores of VR and video training for the knowledge assessment done before the training (Pre), after the training (Post) and after 3/4 weeks (Ret)

\begin{tabular}{llll}
\hline VR versus video & Pre & Post & Ret \\
\hline $\mathrm{N}$ & 92 & 92 & 44 \\
$\mathrm{U}$ & 961.5 & 699 & 86.5 \\
Asymp. sig. (2-tailed) & 0.433 & 0.003 & 0.000 \\
Eta-squared & 0.007 & 0.096 & 0.319 \\
\hline
\end{tabular}

at different stages of the experiment (i.e. Pre, Post and Ret).

The knowledge of the participants before and after the training was statistically different for both groups as there is a significant increment of knowledge, while there is a significant decrease in knowledge when comparing the scores after the training and the scores after $3 / 4$ weeks from the training (see Table 2). The knowledge of participants before the training is not statistically different from zero for the VR and Video groups, while the knowledge for the VR group after the training and after 3-4 weeks is statistically greater than the Video group (see Table 2). Finally, the impact of the effect size is reported in Tables 2 and 3 through the eta-squared parameters which measure the proportion of the total variance that is associated with the membership of different groups.

To verify whether the age difference had an impact on these results, we checked if the difference from knowledge before and after the training was correlated with the age. This was done by a linear regression showing that the influence of age was not statistically significant ( $p$ value $>0.05$ ).

Figure 6 illustrates which information regarding the PASS procedure the participants know before the training, after the training and 3-4 weeks after the training. The results illustrate that the participants of both groups had an increment of their knowledge for each item listed in Fig. 6. However, in line with the results in Fig. 5, the information was not retained for the video group. Finally, it was also observed that participants in the VR group did not retain the PASS acronym. This might be due to the fact the VR application is not designed to ensure participant remembers the PASS acronym by an interactive learning exercise (i.e. learning by doing). In fact, the PASS acronym is visible in the VR application (see Fig. 2), but the application does not provide an interactive learning experience to memorize it. As such, we decided to investigate
Fig. 6 Segregated knowledge data for each evaluated item for both groups

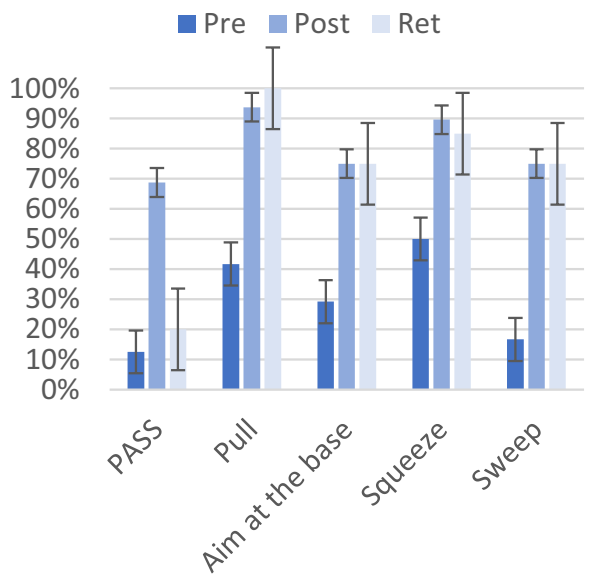

(a) VR group

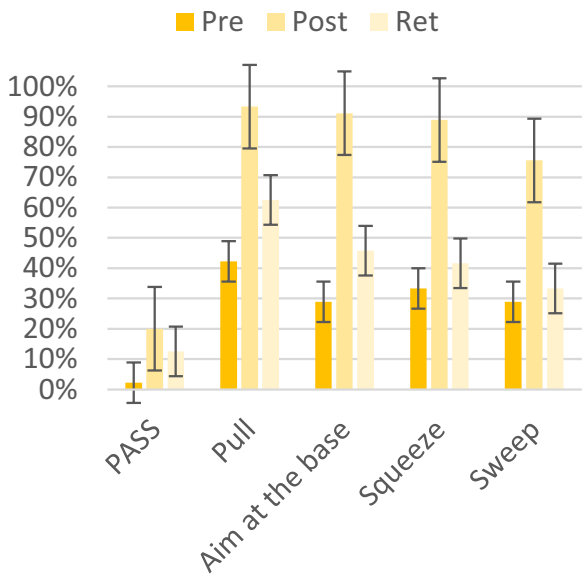

(b) Video group 


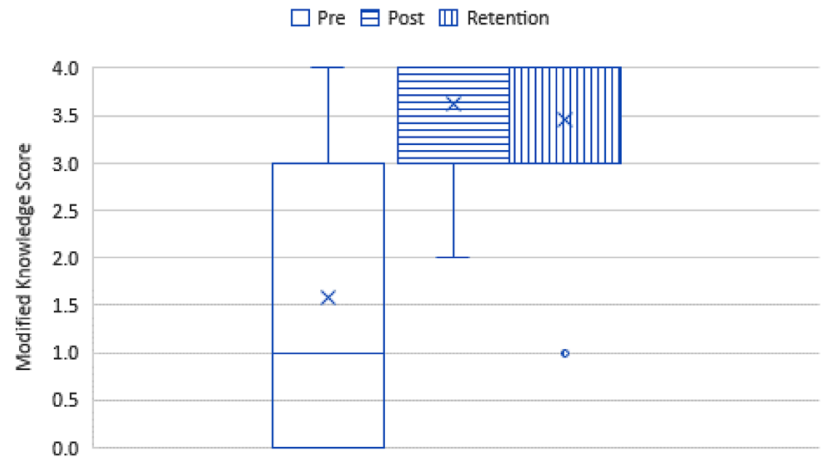

Fig. 7 Modified knowledge scores for the VR group only

Table 4 Comparison of modified knowledge scores before the training (Pre), after the training (Post) and after $3 / 4$ weeks (Ret) for the VR training

\begin{tabular}{lll}
\hline & Pre-Post & Post-Ret \\
\hline $\mathrm{N}$ & 94 & 66 \\
$\mathrm{U}$ & 297 & 445.5 \\
Asymp. sig. (2-tailed) & 0 & 0.808 \\
Eta-squared & 0.429 & 0.001 \\
\hline
\end{tabular}

the knowledge trend using only the items focusing on the interactive learning experience for the VR training without accounting for the PASS item.

Figure 7 illustrates the knowledge scores excluding the PASS item from the knowledge assessment for the VR group. As such, the participants can score between zero and four. Using this modified scoring system, it is possible to observe that there was a significant increment of knowledge after the training regarding the manipulation steps of fire extinguishers (see Table 4); while there is no statistical difference between the knowledge score after the test and after 3/4 weeks (see Table 4). Finally, the impact of the effect size is reported in Table 4 through the eta-squared parameters which measure the proportion of the total variance that is associated with the membership of different groups.

\subsection{Self-efficacy assessment}

In this section, the self-efficacy scores stated by the participants are analysed by averaging them. A Cronbach's Alpha test is used, showing an acceptable level of internal consistency $($ Alpha $=0.74)$. The average scores were analysed by splitting them depending on the group (VR versus Video) and when the assessment occurred, i.e. before the training (Pre), after the training (Post) and after 3/4 weeks (Ret). Given that the self-efficacy is measured using an ordinal scale from -3 to 3 , Mann-Whitney $u$ test was used to compare whether there are statistical differences

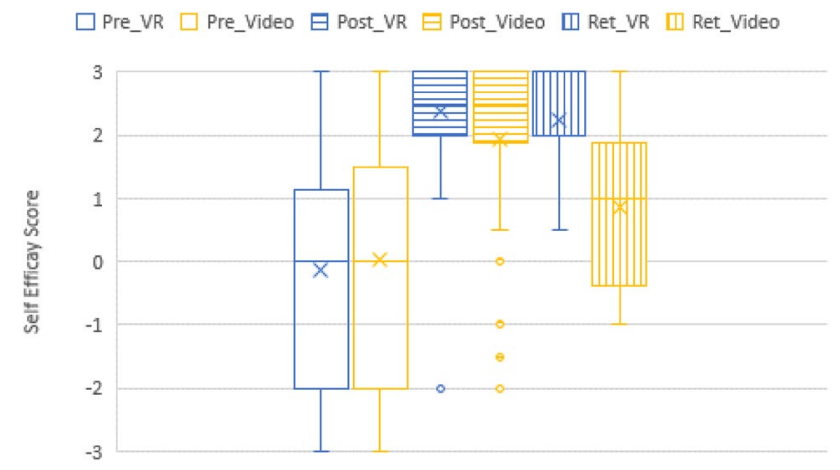

Fig. 8 Self-efficacy scores before the training (Pre), after the training (Post) and after 3/4 weeks (Ret) for the VR and Video training

Table 5 Comparison of self-efficacy scores before the training (Pre), after the training (Post) and after 3/4 weeks (Ret) for the VR and video training

\begin{tabular}{llllll}
\hline & \multicolumn{2}{l}{ Pre versus Post } & & \multicolumn{2}{l}{ Post versus Ret } \\
\cline { 2 - 3 } & VR & Video & & VR & Video \\
\hline $\mathrm{N}$ & 92 & 92 & & 66 & 70 \\
$\mathrm{U}$ & 300 & 425 & & 153 & 554 \\
Asymp. sig. (2-tailed) & 0.000 & 0.000 & & 0.252 & 0.000 \\
Eta-squared & 0.399 & 0.274 & & 0.020 & 0.203 \\
\hline
\end{tabular}

Table 6 Comparison between self-efficacy scores of VR and video training for the knowledge assessment done before the training (Pre), after the training (Post) and after 3/4 weeks (Ret)

\begin{tabular}{llll}
\hline VR versus video & Pre & Post & Ret \\
\hline $\mathrm{N}$ & 92 & 92 & 44 \\
$\mathrm{U}$ & 1011 & 910 & 75 \\
Asymp. sig. (2-tailed) & 0.708 & 0.224 & 0.00 \\
Eta-squared & 0.002 & 0.016 & 0.365 \\
\hline
\end{tabular}

between the experimental groups (i.e. VR and Video) and at different stages of the experiment (i.e. Pre, Post and Ret).

The results are illustrated in Fig. 8. The self-efficacy of the participants before and after the training is statistically different for both groups as there is a significant increment of self-efficacy while there is a significant decrease in selfefficacy when comparing the scores after the training and the scores after 3/4 weeks (see Table 5). The self-efficacy of participants before the training is not statistically different from zero for the VR and Video groups while the self-efficacy for the VR group after the training and after $3 / 4$ week is statistically greater than the Video group (see Table 5). Finally, the impact of the effect size is reported in Tables 5 and 6 through the eta-squared parameters which measure the proportion of 
Fig. 9 Estimated recommendation efficacy and simplicity for the VR and Video groups

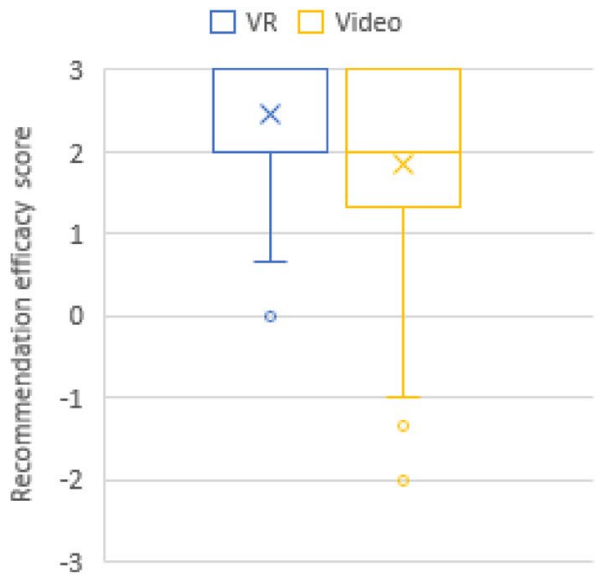

(a)

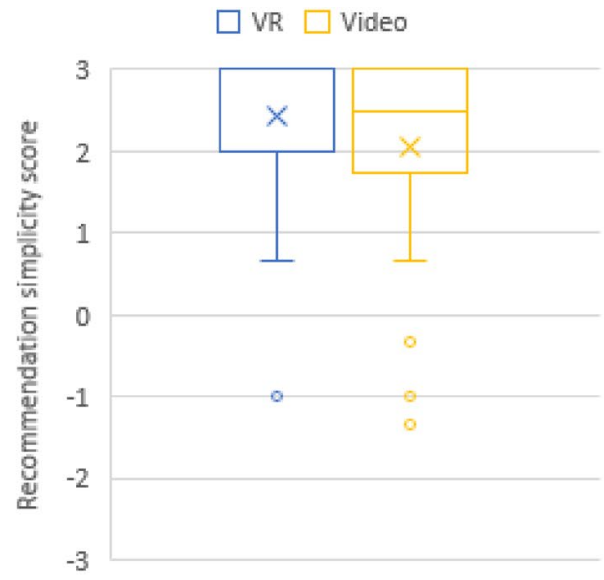

(b)
Table 7 Comparison between recommendation efficacy and simplicity scores of VR and video training

\begin{tabular}{lll}
\hline VR versus video & Efficacy & Simplicity \\
\hline $\mathrm{N}$ & 90 & 90 \\
$\mathrm{U}$ & 760 & 793 \\
Asymp. sig. (2-tailed) & 0.032 & 0.064 \\
Eta-squared & 0.052 & 0.038 \\
\hline
\end{tabular}

the total variance that is associated with the membership of different groups.

To verify whether the age difference had an impact on these results, we checked if the difference from self-efficacy before and after the training was correlated with the age. This was done by a linear regression showing that the influence is not statistically significant ( $p$ value $>0.05$ ).

\subsection{Recommendation assessment}

The perceived recommendation efficacy and simplicity are assessed here for both VR and Video groups by averaging the scores of items described in Sect. 3.4. A Cronbach's Alpha test is used showing good and excellent levels of internal consistency for the efficacy $($ Alpha $=0.88)$ and simplicity (Alpha $=0.91$ ), respectively. Given that the recommendation efficacy and simplicity are measured using an ordinal scale from -3 to 3, Mann-Whitney $u$ test was used to compare whether there are statistical differences between the experimental groups (i.e. VR and Video).

The average scores of recommendation efficacy and simplicity are illustrated in Fig. 9. The statistical tests in Table 7 show that there is a difference for the recommendation efficacy ( $p$ value $<0.05$ ) while there is no difference for the recommendation simplicity ( $p$ value $>0.05$ ). Finally, the impact of the effect size is reported in Table 7 through the eta-squared parameters which measure the proportion

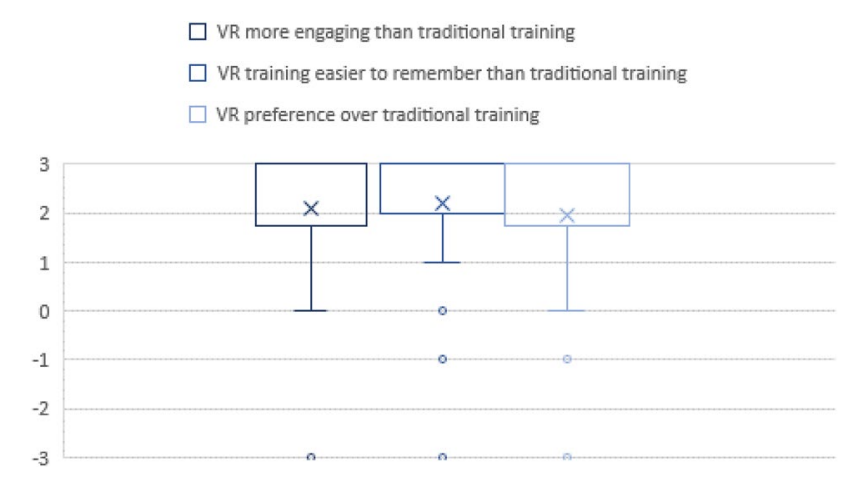

Fig. 10 VR training perception assessment against traditional training by the VR group participants

of the total variance that is associated with the membership of different groups.

\subsection{VR training perception}

This section illustrates how the VR group perceived the VR training compared with traditional training. The results in Fig. 10 indicate that the great majority of the participants who tried VR had a very positive perception. In fact, over $75 \%$ of the sample provided a score greater than one for all the three statements comparing VR training with traditional training.

\section{Discussion}

This work compared the effectiveness of VR and video training on how to use a fire extinguisher according to the PASS procedure. The comparison was made in terms of knowledge acquisition and knowledge retention. Moreover, the comparison of these two training solutions on the basis of Protection Motivation Theory was made by analysing the self-efficacy, 
recommendation efficacy, and recommendation simplicity. Compared with previous studies, this work represents one of the first instances of a comparison of a VR training solution with a traditional training solution (i.e. non-interactable video training) for fire extinguishing as well as the effectiveness of current VR technology for such training.

Focusing on knowledge acquisition and knowledge retention, the results indicate that both training solutions generate a significant increment of knowledge right after the training (see Fig. 5, Table 2). Findings also show that the VR training performs better in terms of knowledge acquisition, i.e. VR participants had a higher score than video participants directly after the training. In terms of knowledge retention, the results indicate that both groups had a decrease in knowledge after a period of 3-4 weeks. However, the data indicates that the amount of information retained by the VR participants was significantly higher than video participants. It is possible to observe that the VR group forgot the acronym "PASS", but they retained the information regarding the individual steps. As such, the knowledge scores for the VR group was compared, excluding the PASS procedure acronym meaning item from the knowledge assessment. Under this assumption, it is possible to observe that the retention knowledge score is not statistically different from the knowledge score right after the training. As such, the results prove the effectiveness of VR training for both knowledge acquisition and retention. This outcome provides further support to the findings by Månsson (2018) who showed the effectiveness of a VR pre-training before operating a real fire extinguisher. As such, this work provided further support for the use of VR training solutions to enhance fire safety preparedness.

From a self-efficacy point of view, the data in Fig. 8 and Tables 5 and 6 show that both training solutions generated a similar increment of self-efficacy (i.e. there is no statistical difference between the two groups before and after the training). However, after 3-4 weeks from the training, the video group showed a significant decrease in self-efficacy while this parameter, while for the VR group, there was no decrease. This second comparison demonstrates that the VR training was more effective than video training. As such, the results indicate that VR training can have a stronger impact on protection motivation. In other words, VR seems to perform better in motivating people to protect themselves from fire threat. However, there could be a risk that people get overly confident and think they can handle a real fire easily just because they managed to extinguish a fire in VR. Thus, using VR is a good complement, but people might need further training with real fire extinguishers on putting out real fires.

This research investigated how the participants assess the recommendation efficacy and simplicity of both training solutions. The results show that the VR group had a higher overall score for recommendation efficacy and simplicity. However, there is a statistical difference only for the recommendation efficacy, while there is no significant difference for the recommendation simplicity. The first result can be justified by the fact that the participants can verify the efficacy of the provided recommendation by actually using them to extinguish the VR fire while the video group cannot as the participant learn passively. Once again, this result indicates that VR seems to perform better in motivating people to protect themselves from a fire threat. The second result (i.e. no difference for the recommendation simplicity) is justified by the fact that both training tools provide the same PASS instructions.

Finally, VR participants were asked to rate the perception of their VR training compared with traditional training. The results in Fig. 10 showed that the majority of the participants recommended the VR training over the traditional training tools. These results indicate that there is great potential for the use of future VR safety training from the users' perspective. However, participant feedback indicated the need for improvement of the VR application regarding game content, game difficulty and game realism. The current application does not allow participants to select the right type of fire extinguishers depending on the source of the fire. Moreover, the application does not teach participants whether the size of the fire is still small enough to be extinguished with the provided device. Finally, participants recommended using controllers that are easier to manipulate. A possible solution could be the one used by Månsson (2018), who modified a real fire extinguisher to be used in the VR simulation.

The main limitation of this study is that all the participants were randomly assigned to the video and VR group; there was an age difference in the two groups. The VR group was slightly older than the Video group. However, this difference did not impact the starting conditions, the pre-existing knowledge on fire extinguishing as well as the starting self-efficacy of the two groups are still, in general, the same (see Figs. 5, 8). Another limitation is that this study does not provide evidence on how different training solutions affect the use of a real fire extinguisher. Moreover, this study used the first generation of VIVE headset, which has a resolution of $1080 \times 1200$ per eye and a field of view of $110^{\circ}$. Future studies need to investigate if higher visual resolutions and field of view can improve the training experience. Other research questions that should be explored is an investigation on the impact of integrating the sensations of heat and smoke odour to the VR experience, to determine if these factors can enhance the VR training for the PASS manoeuvre. Finally, future research is needed to verify whether these findings hold true for any type of safety training as well as to compare immersive VR-based training with non-immersive VR-based training. 


\section{Conclusion}

The main purpose of this work was to compare two alternative solutions for fire extinguisher training. The two solutions were the following: a VR-based fire extinguisher training simulator and a popular YouTube video. Both of the training solutions had the objective of teaching the general public the operation steps of a fire extinguisher (or the PASS procedure). Ninety-three volunteers participated in this study and were divided into two groups. The first group learned from the VR-based training application, while the second group learned from the YouTube video.

The results showed that, compared to video training, the VR training provided a more effective training result in terms of knowledge acquisition and retention, and selfefficacy. This gap is clearly evident after $3-4$ weeks after the training. In addition, the results showed that VR training provided a higher perception of recommendations efficacy and simplicity. Overall, the results identified that the VR-based training tool provided a more effective solution for fire extinguisher training than video training.

Acknowledgements The authors are grateful to MAMMOTH VR and HONE Ltd. for providing the license of the PASS training application. Dr Lovreglio thanks the College of Science of Massey University for funding this research through the MURF fund (Grant No. SREF). Finally Dr Lovreglio would like to thank Phil Jackson (EvacuationNow) and the Fire Protection Association (NZ Chapter) for helping with the data collection.

\section{Compliance with ethical standards}

Ethical approval All objectives of the experiment were achieved with low ethics level, according to the Massey University's Code of Ethics. Participants were informed (1) about the purpose of the study, (2) that they had the right to stop the experiment at any time without providing any reason and (3) that they can stop the experiment if they felt sick or any discomfort. All the training sessions were performed under the supervision of a researcher, in case there was any emergency.

Informed consent A Participant information sheet and consent form were signed by all participants before undertaking the VR or video training.

\section{References}

Bass A (2014) PASS - fire extinguisher safety (a YouTube video). https://www.youtube.com/watch?v=6NMUuteWvRo. Accessed 17 July 2019

Burigat S, Chittaro L (2016) Passive and active navigation of virtual environments vs. traditional printed evacuation maps: a comparative evaluation in the aviation domain. Int J Hum Comput Stud 87:92-105. https://doi.org/10.1016/j.ijhcs.2015.11.004

Cha M, Han S, Lee J, Choi B (2012) A virtual reality fire training simulator integrated with fire dynamics data. Fire Saf J $50: 12-24$
Chittaro L (2016) Designing serious games for safety education: "Learn to Brace" vs. Traditional Pictorials for Aircraft Passengers. Proc IEEE Trans Vis Comput Gr 22(5):1527-1539

Chittaro L, Buttussi F (2015) Assessing knowledge retention of an immersive serious game vs. a traditional education method in aviation safety. IEEE Trans Vis Comput Gr 21(4):529-538. https://doi.org/10.1109/tvcg.2015.2391853

Chittaro L, Ranon R (2009) Serious games for training occupants of a building in personal fire safety skills. In: Proceedings of VSGAMES'09: IEEE first international conference on games and virtual worlds for serious applications, IEEE Computer Society Press, Los Alamitos, CA, USA, pp 76-83

Chittaro L, Sioni R (2015) Serious games for emergency preparedness: evaluation of an interactive vs. a non-interactive simulation of a terror attack. Comput Hum Behav 50:508-519

Chittaro L, Corbett CL, McLean GA, Zangrando N (2018) Safety knowledge transfer through mobile virtual reality: a study of aviation life preserver donning. Saf Sci 102:159-168. https:// doi.org/10.1016/j.ssci.2017.10.012

De Gloria A, Bellotti F, Berta R (2014) Serious games for education and training. Int J Serious Games. https://doi.org/10.17083 /ijsg.v1i1.11

Duckworth S, Thompson A, Young B (2016) International good practice in safety, health and wellbeing in fire and emergency services. A case study analysis. New Zealand Fire Service Research Report

Feng Z, Gonzalez V, Amor R, Lovreglio R et al (2018) Immersive virtual reality serious games for evacuation training and research: a systematic literature review. Comput Educ. https:// doi.org/10.1016/j.compedu.2018.09.002

Inoue Y (1999) Effects of virtual reality support compared to video support in a high-school world geography class. Campus-Wide Inf Syst 16(3):95-104. https://doi.org/10.1108/10650749910281250

Kim JH, Park ST, Lee H, Yuk KC, Lee H (2001) Virtual reality simulations in physics education. http://imej.wfu.edu/articles/2001/2/02/ index.asp

Kinateder M, Pauli P, Müller M, Krieger J, Heimbecher F, Rönnau I, Bergerhausen U, Vollmann G, Mühlberger A (2013) Human behaviour in severe tunnel accidents: effects of information and behavioural training. Trans Res Part F Traffic Psychol Behav 17:20-32. https://doi.org/10.1016/j.trf.2012.09.00

Kinateder M, Müller M, Jost M, Mühlberger A, Pauli P (2014) Social influence in a virtual tunnel fire-influence of conflicting information on evacuation behaviour. Appl Ergonom 45:1649-1659

Lebram M et al (2009) Design and architecture of Sidh-a cave based firefighter training game. Design and use of serious games Springer, Dordrecht, pp 19-31

Leder J, Horlitz T, Puschmann P, Wittstock V, Schütz A (2019) Comparing immersive virtual reality and powerpoint as methods for delivering safety training: impacts on risk perception, learning, and decision making. Saf Sci 111:271-286

Lee EAL (2011) An investigation into the effectiveness of virtual reality-based learning. Ph.D. thesis, Murdoch University

Lovreglio R, Kinateder M (2020) Augmented reality for pedestrian evacuation research: promises and limitations. Saf Sci. https:// doi.org/10.1016/j.ssci.2020.104750

Lovreglio R, Gonzalez V, Feng Z, Amor R, Spearpoint M, Thomas J, Trotter M, Sacks R (2018) Prototyping Virtual reality serious games for building earthquake preparedness: the Auckland city hospital case study. Adv Eng Inform. https://doi.org/10.1016/j. aei.2018.08.018

Maddux JE, Rogers RW (1983) Protection motivation and self-efficacy: a revised theory of fear appeals and attitude change. J Exp Soc Psychol 19(5):469-479

Månsson J (2018) Using a virtual fire extinguisher as a tool for safety training. Master Thesis, Faculty of Engineering, Lund University 
NZG-New Zealand Government. Commercial use of fire extinguishers. https://fireandemergency.nz/business-and-landlords/comme rcial-use-of-fire-extinguishers/. Accessed 17 July 2019

Poole B, Hicks WD, Notarianni KA, Hanks C, Harris R, Gorbett GE (2012) Ordinary people and effective operation of fire extinguishers. Worcester Polytechnic Institute. http://www.femalifesafety. org/docs/wpistudyfinal.pdf

Rüppel U, Schatz K (2011) Designing a BIM serious game for fire safety evacuation simulations. Adv Eng Inform 25:600-611

Silva JF, Almeida JE, Rossetti RJF, Coello AL (2013) A serious game for evacuation training. In: Proceedings of IEEE 2nd international conference on serious games and application for health (SeGAH2013). Vilamoura, Algarve, Portugal

Smith S, Ericson E (2009) Using immersive game virtual reality to teach fire-safety skills to children. Virtual Real 13(2):87-99. https ://doi.org/10.1007/s10055-009-0113-6

Smith SP, Trenholme D (2009) Rapid prototyping a virtual fire drill environment using computer game technology. Fire Saf J 44(4):559-569

Taitt HA (1993) Technology in the classroom: planning for educational change. Curriculum Report Vol. 22 No. 4, National Association of Secondary School Principals, Reston, VA (ERIC Document Reproduction Service No. 359 922)

Tate DL, Sibert L, King T (1997) Virtual environments for shipboard firefighting training. In: Proceedings of IEEE 1997 annual international symposium on virtual reality. Albuquerque, NM, USA, pp 61-68. https://doi.org/10.1109/vrais.1997.583045

Trusted Reviews (2018) Can your PC run the HTC Vive? Minimum system requirements revealed. https://www.trustedreviews.com/ news/can-i-run-the-htc-vive-2936671. Accessed July 17 July 2019

Xu Z, Lu XZ, Guan H, Chen C, Ren AZ (2014) A virtual reality fire training simulator with smoke hazard assessment capacity. Adv Eng Softw 68:1-8

Publisher's Note Springer Nature remains neutral with regard to jurisdictional claims in published maps and institutional affiliations. 